\title{
Mechanical Properties of Fiber-Reinforced Soil under Triaxial Compression and Parameter Determination Based on the Duncan-Chang Model
}

\author{
Yingying Zhao ${ }^{1,2,3} \mathbb{0}$, Xianzhang Ling ${ }^{3,4, *}$, Weigong Gong ${ }^{1,2}$, Peng Li ${ }^{5}$, Guoyu Li ${ }^{6}$ \\ and Lina Wang ${ }^{7}$ \\ 1 Key Laboratory of Concrete and Prestressed Concrete Structures of Ministry of Education, \\ Southeast University, Nanjing 211189, China; zhaoyingying@seu.edu.cn (Y.Z.); wmgong@seu.edu.cn (W.G.) \\ School of Civil Engineering, Southeast University, Nanjing 211189, China \\ 3 School of Civil Engineering, Harbin Institute of Technology, Harbin 150090, China \\ 4 School of Civil Engineering, Qingdao University of Technology, Qingdao 266033, China \\ 5 School of Civil and Architectural Engineering, East China University of Technology, \\ Nanchang 330013, China; hit_lipeng@ecut.edu.cn \\ 6 State Key Laboratory of Frozen Soil Engineering, Northwest Institute of Eco-Environment and Resources, \\ Lanzhou 730000, China; guoyuli@lzb.ac.cn \\ 7 School of Construction Engineering, Yunnan Agricultural University, Kunming 650201, China; \\ wlnyongji@126.com \\ * Correspondence: lingxianzhang@hit.edu.cn
}

Received: 8 November 2020; Accepted: 16 December 2020; Published: 17 December 2020

\begin{abstract}
To study the mechanical properties of Y-shaped polypropylene fiber-reinforced subgrade fill, the strength characteristics of fiber-reinforced soil with different fiber contents, fiber lengths, and confining pressures were investigated through triaxial compression tests. The test results showed that fiber reinforcement significantly improved the strength and cohesion of the subgrade fill but had a limited impact on the internal friction angle. The fiber-reinforced soil specimens exhibited a failure pattern of bulging deformation, showing plastic failure characteristics. As the fiber content and length increased, the strength of the fiber-reinforced soil increased and then decreased. The optimal fiber content was $0.2 \%$, and the optimal fiber length was between 12 and $18 \mathrm{~mm}$ in all test conditions. The strength of the fiber-reinforced soil increased with increasing confining pressure. An empirical model for predicting the failure strength of fiber-reinforced soil was established by analyzing the relationships between the failure strength of the fiber-reinforced soil and the fiber content, fiber length, and confining pressure. The stress-strain relationship of the fiber-reinforced soil exhibited strain-hardening characteristics and could be approximated by a hyperbolic curve. The Duncan-Chang model could be used to describe the stress-strain relationship of this fiber-reinforced soil. A calculation method to determine the model parameters (initial tangent modulus and ultimate deviator stress) was proposed.
\end{abstract}

Keywords: fiber-reinforced soil; triaxial compression test; strength characteristics; Duncan-Chang model; model parameters

\section{Introduction}

A widely used method for subgrade reinforcement is horizontal fiber reinforcement. The reinforcement direction and spacing can cause weak interfaces, such that only the lateral deformation of the subgrade can be controlled, and the problem of subgrade settlement deformation cannot be controlled. Therefore, three-dimensional (3D) fiber reinforcement for subgrade projects has been 
introduced. This kind of fiber reinforcement is a geotechnical composite technology that mixes short fibers or continuous fibers randomly and discretely into the soil [1] to improve the mechanical properties of the soil through the friction between the fiber and soil and between the fibers in the 3D reticulated fiber system [2,3], and has been popularized and applied in reinforcement projects such as subgrades, side slopes, and retaining walls.

In recent years, scholars have carried out a series of theoretical and experimental research studies on the mechanical and engineering properties of fiber-reinforced soil. Botero et al. [4] studied the mechanical properties of recycled poly (ethylene terephthalate) (PET) fiber-reinforced silt through triaxial shear tests and found that the fibers enhanced the resistance of soil to deformation. Through triaxial and durability tests, Muntohar et al. [5] found that fiber-enforced soil had significantly better shear, compressive, and tensile strengths, showing enhanced stability and durability. The reinforcement was the most effective at a fiber content of $0.4-0.8 \%$. From triaxial tests, Machado et al. [6] found that the stress-strain curve of fiber-reinforced garbage soil showed a strain-hardening characteristic, and the incorporation of fibers significantly improved the shear strength of the garbage soil. Kutara et al. [7] investigated, through triaxial tests, the shear strength characteristics of continuous fiber-reinforced soil and their influencing factors and found that the fiber content had the most significant influence among the studied parameters and can substantially improve cohesion. You et al. [8] ran triaxial tests to study the stress-strain characteristics and fiber reinforcement effect of expansive soil reinforced with basalt fiber and found that the stress-strain curve possessed strain-hardening characteristics, and a higher confining pressure led to higher strength, with an optimal fiber content of $0.4 \%$. The incorporated fiber significantly increased the cohesion of the expansive soil, while the changes in the internal friction angle were small. Gao et al. [9] found that the stress-strain curve possessed weak hardening characteristics and could be fitted by a hyperbolic curve. The basalt fiber reinforcement had little effect on the effective internal friction angle of the clay, though the effective cohesion was significantly increased, suggesting an optimal fiber content of $0.3 \%$. Through triaxial tests, Liu et al. [10] found that the strength of glass fiber-reinforced soil increased with increases in the fiber length, fiber content, confining pressure, and soil compactness, but an increase in water content had the opposite effect. Mirzababaei et al. [11] tested the unconfined compressive strength of waste carpet fiber-reinforced soil and found that the fibers increased the unconfined compressive strength, and the resilience of the soil was effectively improved, with an optimal fiber content of $5 \%$. Through the unconfined compressive testing of fiber-reinforced soil, Akbulut et al. [12] found that for polypropylene fiber-reinforced soil, the optimal fiber content was $0.2 \%$, and the optimal fiber length was $15 \mathrm{~mm}$; however, for rubber fiber-reinforced soil, the optimal fiber content was $2 \%$, and the optimal fiber length was $10 \mathrm{~mm}$. Consoli et al. [13] studied the effects of fiber length and content on the shear strength of fiber-reinforced soil and found that with increasing fiber length and content, the contact area between the fibers and soil particles increased, and the shear strength increased significantly. Thus, existing research has shown that the strength of fiber-reinforced soil is influenced by factors such as fiber characteristics, soil properties, and external factors, with fiber content having the most significant effect $[14,15]$.

Research on fiber-reinforced soil has mainly focused on the reinforcement effect and soil mechanical properties, while research on strength prediction and building constitutive models for fiber-reinforced soils is relatively rare. This study conducted a series of triaxial compression tests on polypropylene fiber-reinforced subgrade fill to analyze the effects of three parameters, namely, fiber content, fiber length, and confining pressure, on the stress-strain relationship and failure strength. Furthermore, this study established an empirical model for predicting the failure strength of fiber-reinforced soil and determined the best mechanical model and parameter calculation method. The results of this paper can provide technical guidance for the engineering of reinforced railway subgrade. 


\section{Materials}

\subsection{Soil Samples}

The material used in the test was taken from the subgrade fill of the Bazhun heavy-haul railway in Ordos city, Inner Mongolia, China. According to the "Code for Design on Subgrade of Railway" (TB10001-2005), the subgrade fill is classified as Group A fill, which is well-graded coarse sand. The sand fill is inorganic, with the organic matter content $w_{\mathrm{u}}$ of $2.21 \%<5 \%$ (determined by ignition loss test). The mineral content of the sand is $82 \%$ quartz, with small amounts of plagioclase, illite, plagioclase, barite, and sphalerite at 5\%,4\%, 2\%, 4\%, and 3\%, respectively. Its particle size distribution is shown in Table 1 and Figure 1. The optimal water content and maximum dry density of the fill material were determined by the heavy compaction test, and the physical and mechanical properties of the fill material are listed in Table 2. According to the "Code for Design of Heavy-haul Railway" (TB10625-2017), the dynamic deformation modulus of Group A fill is $\geq 40.3 \mathrm{MPa}$, and the mean deformation modulus of this subgrade fill is $19.23 \mathrm{MPa}$, indicating that it is initially unsuitable as heavy-haul railway subgrade fill and that there is a need for reinforcement treatment. Therefore, the fiber reinforcement method was tested.

Table 1. Particle size distribution of subgrade fill.

\begin{tabular}{ccccccccc}
\hline Particle Size $(\mathbf{m m})$ & $\mathbf{> 1 0}$ & $\mathbf{1 0 - 5}$ & $\mathbf{5 - 2}$ & $\mathbf{2 - 1}$ & $\mathbf{1 - 0 . 5}$ & $\mathbf{0 . 5 - 0 . 2 5}$ & $\mathbf{0 . 2 5 - 0 . 0 7 5}$ & $\leq \mathbf{0 . 0 7 5}$ \\
\hline Percentage $(\%)$ & 1.13 & 10.129 & 11.234 & 27.7 & 15.613 & 13.144 & 18.188 & 2.862 \\
\hline
\end{tabular}

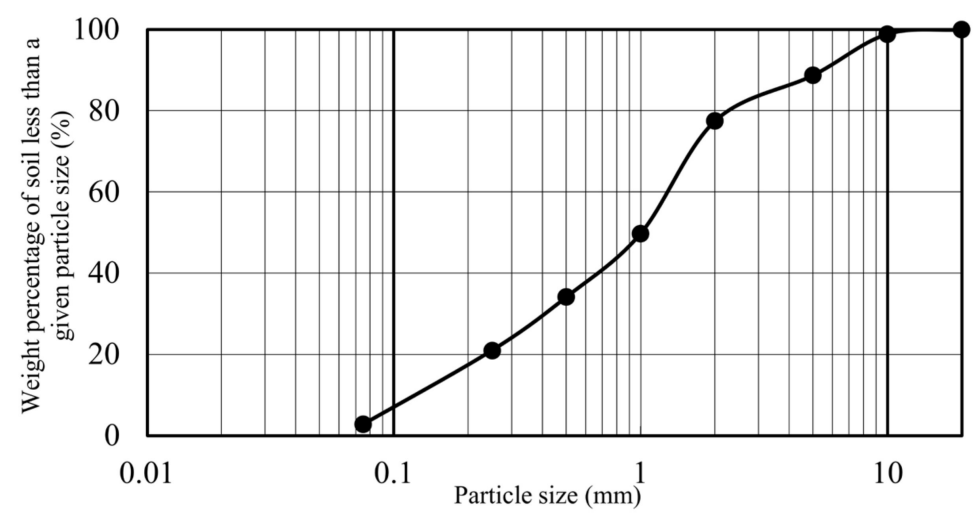

Figure 1. Particle analysis curve of subgrade fill.

Table 2. Physical and mechanical properties of subgrade fill.

\begin{tabular}{|c|c|c|c|c|c|c|c|c|}
\hline $\begin{array}{l}\text { Optimal } \\
\text { Water } \\
\text { Content } \\
(\%)\end{array}$ & $\begin{array}{c}\text { Maximum } \\
\text { Dry } \\
\text { Density } \\
\left(\mathrm{g} / \mathrm{cm}^{3}\right)\end{array}$ & $\begin{array}{l}\text { Maximum } \\
\text { Porosity }\end{array}$ & $\begin{array}{l}\text { Minimum } \\
\text { Porosity }\end{array}$ & $\begin{array}{l}\text { Cohesion } \\
\text { (MPa) }\end{array}$ & $\begin{array}{c}\text { Internal } \\
\text { Friction } \\
\left.\text { Angle ( }{ }^{\circ}\right)\end{array}$ & $\begin{array}{c}\text { Dynamic } \\
\text { Deformation } \\
\text { Modulus } \\
\text { (MPa) }\end{array}$ & $\begin{array}{l}\text { Nonuniformity } \\
\text { Coefficient }\end{array}$ & $\begin{array}{l}\text { Radius of } \\
\text { Curvature }\end{array}$ \\
\hline 8.5 & 2.06 & 1.004 & 0.613 & 0 & 38 & 19.23 & 10.89 & 1.02 \\
\hline
\end{tabular}

\subsection{Polypropylene Fiber}

The fibers used in the test were monofilament polypropylene fibers in bundles, produced by Shanghai Bonin Engineering Fiber Materials Co. LTD, Shanghai, China. It can be cut into the required length for the test. Generally, the length of cut fiber is 3, 6, 9, 12, 15, and $18 \mathrm{~mm}$, and other lengths can be ordered in advance. The fiber length error can be controlled within $5 \%$. It is worth pointing out that the fibers used in this study are of Y-shaped cross-section. The appearance morphology and cross-sectional dimensions of the fibers are shown in Figure 2. In order to exert the effect of fiber reinforcement, the polypropylene fiber used in this test was modified by acid and alkali surface treatment, which can make the fiber surface form a protective layer of organic reagent to prevent surface oxidation and mechanical damage, change the surface performance of synthetic fiber, thus increasing the surface 
roughness of fiber, improving the surface hydrophilicity of fiber and the bonding strength of the interface with soil base. These fibers have good tensile properties, are highly resistant to acids, bases, and salts, have low thermal and electrical conductivities, have an excellent dispersibility, are safe and nontoxic, and are inexpensive; thus, polypropylene fibers have been promoted in engineering applications. Their physical and mechanical properties are given in Table 3.

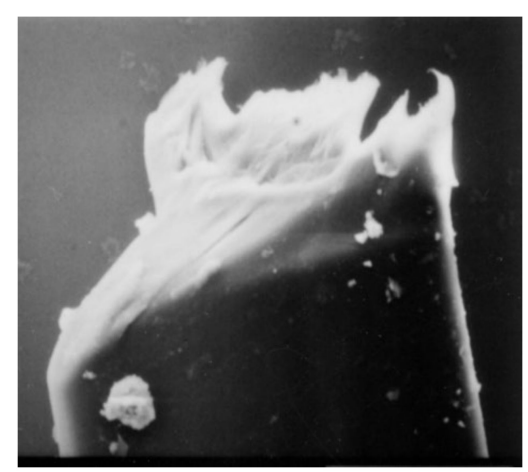

(a)

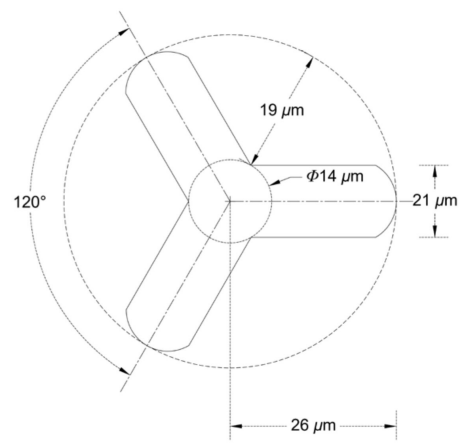

(b)

Figure 2. Appearance morphology and cross-sectional dimensions of Y-shaped fibers: (a) Appearance morphology; (b) Cross-sectional dimensions.

Table 3. Physical and mechanical properties of polypropylene fibers.

\begin{tabular}{lccccccc}
\hline Fiber Type & $\begin{array}{c}\text { Density } \\
\left(\mathrm{g} / \mathrm{cm}^{3}\right)\end{array}$ & $\begin{array}{c}\text { Diameter } \\
(\mu \mathrm{m})\end{array}$ & $\begin{array}{c}\text { Melting } \\
\text { Point }\left({ }^{\circ} \mathrm{C}\right)\end{array}$ & $\begin{array}{c}\text { Flash } \\
\text { Point }\left({ }^{\circ} \mathrm{C}\right)\end{array}$ & $\begin{array}{c}\text { Elongation } \\
\text { at Break } \\
(\%)\end{array}$ & $\begin{array}{c}\text { Modulus of } \\
\text { Elasticity } \\
(\mathrm{GPa})\end{array}$ & $\begin{array}{c}\text { Tensile } \\
\text { Strength } \\
\mathbf{( M P a})\end{array}$ \\
\hline $\begin{array}{c}\text { Monofilament } \\
\text { Y-type }\end{array}$ & 0.91 & 31 & $165-170$ & 590 & 30 & $\geq 3.5$ & $\geq 350$ \\
\hline
\end{tabular}

\section{Design of the Test}

\subsection{Specimen Preparation}

The subgrade fill of the Bazhun heavy-haul railway taken from the site was air-dried, crushed, and passed through a 10-mm sieve. Before mixing, the polypropylene fibers, air-dried soil, and water required for each sample were divided into five parts according to the design conditions. Each set of materials was mixed separately, and then the five parts were mixed together to ensure the maximum uniformity of fiber distribution in the soil. To compare the reinforcement effects under same conditions before and after fiber reinforcement, the moisture content of the fiber reinforced soil was adjusted to the water content of $8.5 \%$. In order to guarantee the uniformity of fibers within the sample distribution and the homogeneity of material, the moist tamping technique, widely used to prepare non-cohesive fiber reinforced soil, was used to prepare fiber soil samples, which can well mix fibers and soil, and its effectiveness has been verified by a large number of experiments conducted by Michalowski and Russell [16], Wood et al. [17], Ibraim et al. [18,19], and Diambra et al. [20]. This mixing method can effectively solve the problem of fiber winding and floating. The fiber-reinforced soil samples were mixed well, stored in a plastic bag, sealed, and left for $24 \mathrm{~h}$ so that the water in the soil would fully and evenly disperse. The fiber-reinforced soil sample preparation used the bidirectional static pressure method. The samples were all prepared with a compacting factor of 0.97 . For reinforced samples, the compacting factor was controlled by mixing the same mass of dry soil as a plain soil sample with a given mass of fibers and compressing to a volumetrically consistent sample. At the same time, according to Ang and Loehr [21], when the sample diameter is greater than or equal to $70 \mathrm{~mm}$ and the fiber length is no more than $50 \mathrm{~mm}$, mechanical properties can be ignored by the size effect. To avoid the size effect, the size of the sample in this study is determined by the size of the test fixture. The sample height was $125 \mathrm{~mm}$, and the diameter was $61.8 \mathrm{~mm}$. 


\subsection{Test Scheme and Instrumentation}

This test adopted a strain-controlled triaxial shear apparatus equipped with data acquisition and control systems to carry out unconsolidated and undrained tests. The polypropylene fiber-reinforced subgrade fill was used as the object of study. The polypropylene fiber was mixed into the subgrade fill with contents of $0 \%, 0.1 \%, 0.2 \%$, and $0.3 \%$ (weight percentage with respect to dry soil) and with lengths of $0 \mathrm{~mm}, 3 \mathrm{~mm}, 9 \mathrm{~mm}, 12 \mathrm{~mm}$, and $18 \mathrm{~mm}$ to explore the effects of fiber reinforcement on the strength, deformation, and Duncan-Chang parameters of the subgrade fill, i.e., the effect of the fiber reinforcement. In this study, a total of 11 groups of tests were conducted, with three samples in each group under the same condition, and the average of the test results of the three samples was taken as the representative values of the test results under the condition. During the tests, the applied confining pressure was $0.1 \mathrm{MPa}, 0.3 \mathrm{MPa}, 0.5 \mathrm{MPa}$, or $0.7 \mathrm{MPa}$, and the shear rate was $1.25 \mathrm{~mm} / \mathrm{min}$. When the axial strain reached $15 \%$, the test was stopped. The specific test scheme is shown in Table 4 .

Table 4. Triaxial compressive test conditions.

\begin{tabular}{ccccc}
\hline Soil Type & $\begin{array}{c}\text { Confining } \\
\text { Pressure (MPa) }\end{array}$ & Fiber Content (\%) & Fiber Length (mm) & Test Number \\
\hline & & 0 & & M1 \\
& 0.1 & 0.1 & 12 & M3 \\
& & 0.2 & & M5 \\
& & 0.3 & 0 & L1 \\
Fill/Fiber-reinforced & 0.1 & & 3 & L2 \\
soil & & 0.2 & 9 & L3 \\
& & & 12 & L5 \\
& 0.1 & & & WY1 \\
& 0.3 & 0.2 & 12 & WY2 \\
& 0.5 & & & WY3 \\
\end{tabular}

\section{Analysis of Test Results}

\subsection{Stress-Strain Relationship Analysis of Fiber-Reinforced Soil}

The stress-strain curves of the fiber-reinforced soil show that for the fill mixed with fibers, the shape of the stress-strain curve did not change from that without fibers and still possessed strain-hardening characteristics $[6,8,9]$, but the degree of hardening was enhanced. The effect of fiber incorporation on the mechanical properties of the fill showed that as the cohesion increased from $0 \mathrm{MPa}$ to $0.11 \mathrm{MPa}$, the internal friction angle decreased from $38^{\circ}$ to $37.7^{\circ}$. Compared with the change in the internal friction angle, the increase in cohesion was even more pronounced with fiber incorporation, which is consistent with References [7-9,22]. When the strain remained unchanged, the addition of fiber significantly increased the stress in the fill, indicating that fiber incorporation significantly enhanced the strength and stiffness of the fill, for an excellent reinforcement effect.

The shear failure pattern of the fill did not change with the incorporation of fiber; the failure was still due to bulging deformation. The lateral deformation, which was large in the middle and small at the two ends of each specimen, showed plastic failure characteristics and no obvious cracks or failure in the surface [8,9] (Figure 3). The analysis results showed that the fibers were randomly and disorderly dispersed in the soil, forming a 3D reticulated structure, which enhanced the frictional force and occlusal force of the fill. Fiber with good tensile reinforcement due to fiber bridging can bear part of the tensile stress, bear the external load, and transfer its force, inhibit the generation and development of microcracks, strengthen the soil integrity, and improve the ability of the soil to resist deformation and failure [8]. 


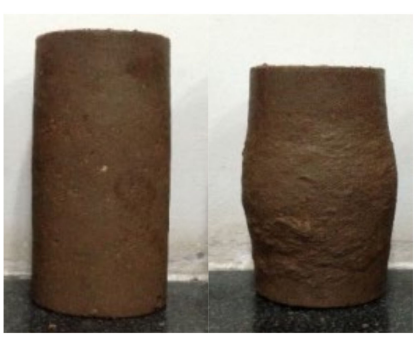

(a)

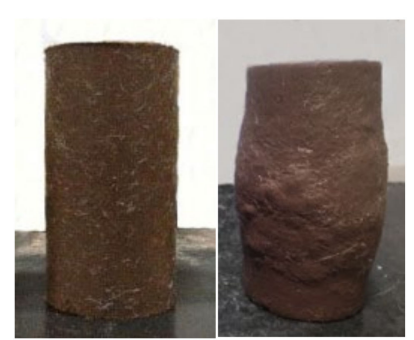

(b)

Figure 3. Failure characteristics of subgrade fill and fiber-reinforced soil samples: (a) Fill; (b) Fiber-reinforced soil.

\section{(1) Effect of fiber content}

The stress-strain curves of the fiber-reinforced soil with different fiber contents (Figure 4) show that when the strain remained unchanged, as the fiber content increased, the stress of the fiber-reinforced soil first increased and then decreased. When the fiber content was between $0 \%$ and $0.2 \%$, the fibers filled the voids in the original soil skeleton. With the increase in fiber content, the compactness increased, the frictional force and occlusal force of the soil body were enhanced, and the constraint of the reticulated structure created by the fibers in the soil was strengthened, which enhanced the soil's load transfer and dispersion abilities. Therefore, a fiber content up to $0.2 \%$ enhanced the strength. When the fiber content was greater than $0.2 \%$, the fibers in the soil were in an oversaturated state, and the fibers occupied the space of the original soil particles. As the fiber content increased, the compactness of the soil decreased, the rate of fiber entanglement and floating increased, the uniformity and effective reinforcement ratio decreased, and the reinforcement effect was weakened [23]. Thus, the strength decreased as the fiber content increased above $0.2 \%$.

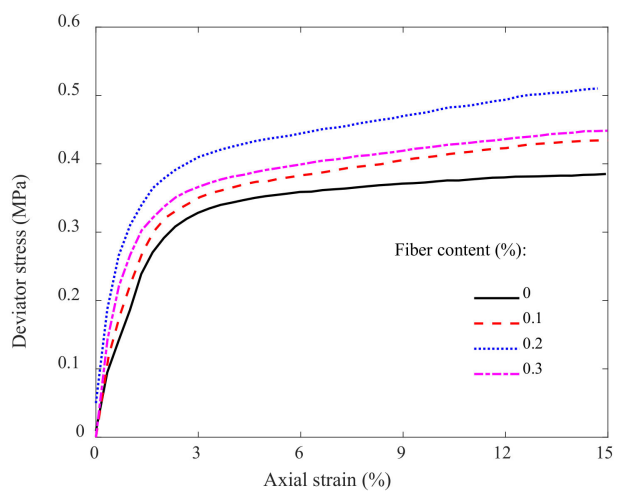

Figure 4. Stress-strain relationships of the fiber-reinforced soil with different fiber contents.

The above analysis shows that there should be an optimal fiber content in fiber-reinforced soil. Here, the best reinforcement effect was achieved at a fiber content of $0.2 \%$, which is in agreement with the findings of many experimental studies $[5,8,9,11,12,24,25]$. This study found that the optimal fiber content varied depending on the soil properties, fiber type, and particle size but was mostly in the range of $0.1-0.3 \%[12,26-28]$.

\section{(2) Effect of fiber length}

The stress-strain curves of the fiber-reinforced soil with different fiber lengths (Figure 5) showed that when the fiber length was $0-12 \mathrm{~mm}$, the strength of the fiber-reinforced soil increased with fiber length, and when the fiber length was greater than $12 \mathrm{~mm}$, the strength of the fiber-reinforced soil decreased with the increase in fiber length. This suggests that there is an optimal fiber length for the fiber-reinforced soil. The best reinforcement effect was achieved when the length was $12 \mathrm{~mm}$, which is 
consistent with the conclusions of other studies [12,24]. At the same time, the optimal fiber length in many studies was 10-15 $\mathrm{mm}[22,25,29-32]$.

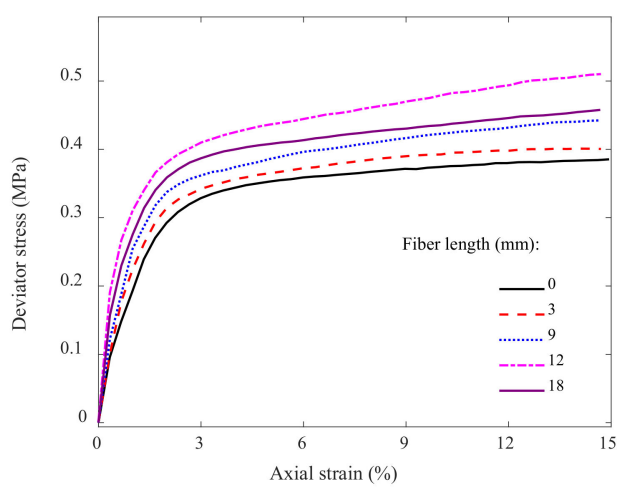

Figure 5. Stress-strain relationships of soils reinforced with fibers of different lengths.

The above analysis shows that the optimal fiber length is in the range of $12-18 \mathrm{~mm}$. This length can avoid the problems of fiber twisting, agglomeration, and floating due to the long lengths of the monofilament bundles and the problem of its inability to form a 3D reticulated structure due to the fiber lengths being too short. In the force-induced deformation process of reinforced soil specimens with 12-mm-long fibers, with a continuously increasing load, the fiber approached the critical state of sliding, pulling out, and breaking, and the frictional and occlusal forces in the soil approached the tensile strength of the fiber itself. At this time, the fiber reinforcement effect was optimal. Therefore, the choice of fiber length is particularly important. When the length is optimal, the fiber is close to the critical state, the tensile strength of the fiber and its tensile stress in the soil are similar, and the fiber reinforcement effect is the best [33].

\section{(3) Effect of confining pressure}

The stress-strain curves of the fiber-reinforced soil under different confining pressures (Figure 6) showed that at the beginning of loading, as the strain increased, the stress of the fiber-reinforced soil under different confining pressures stayed basically the same, which meant that the contribution of the confining pressure to the fiber reinforcement effect was small when the strain was small. As the load continued to increase, with the increase in the confining pressure, the stress of the fiber-reinforced soil increased rapidly, and the confining pressure had a significant effect on the strength of the fiber-reinforced soil. That is, the higher the confining pressure was, the better the reinforcement effect. This is because when the confining pressure was high, the ability to confine the lateral deformation of the soil was strong, and the voids in the soil closed quickly. The fibers could effectively distribute the shear stress in the soil, change the forms of the external load forces, and optimize the force structure. The stronger the constraint on the soil was, the better the fiber reinforcement effect.

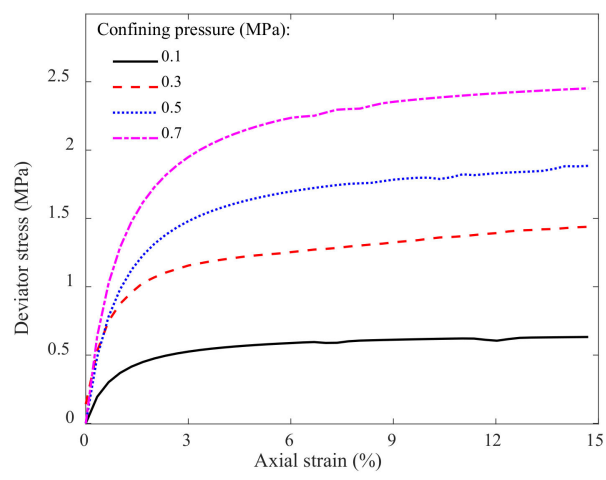

Figure 6. Stress-strain relationships of the fiber-reinforced soil under different confining pressures. 


\subsection{Analysis of the Failure Strength of Fiber-Reinforced Soil and the Empirical Prediction Model}

To better predict the strength characteristics of the fiber-reinforced soil at the time of failure, the stress-strain relationship of the fiber-reinforced soil was obtained from the triaxial tests, and the stress value corresponding to $15 \%$ of the axial strain was taken as the failure stress.

\section{(1) Effect of fiber content}

Figure 7 shows the relationship between the failure stress and the fiber content for the fiber-reinforced soil with 12-mm-long fibers. The failure stress of fiber-reinforced soil did not increase with the increase in fiber content; instead, it first increased and then decreased, approximating a sinusoidal trigonometric function, which indicated an optimal fiber content. When the fiber content was $0.2 \%$, the failure strength of the fiber-reinforced soil peaked.

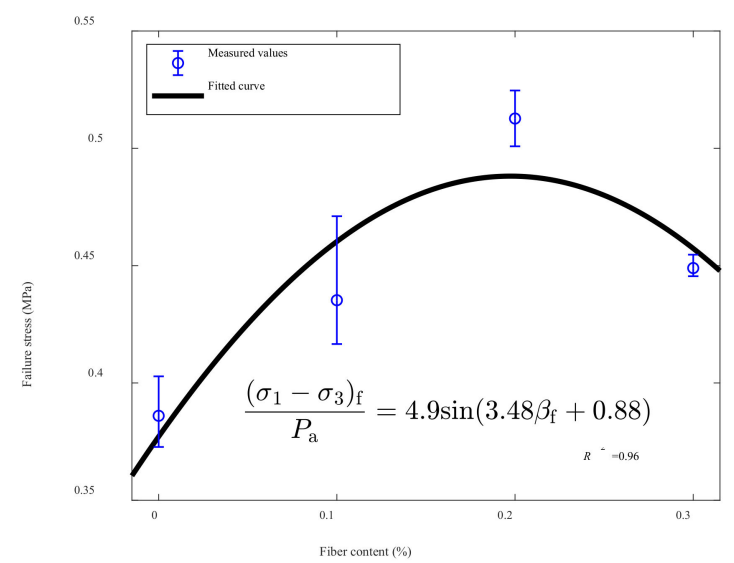

Figure 7. Relationship between the failure stress and fiber content of the fiber-reinforced soil.

(2) Effect of fiber length

Figure 8 shows the relationship between the failure stress and the fiber length of the fiber-reinforced soil with a fiber content of $0.2 \%$. As fiber length increased, the failure stress of the fiber-reinforced soil first increased and then decreased, approximating a Gaussian function. This indicates that when the fiber length is too long or too short, the fiber length limits the failure strength of the fiber-reinforced soil. That is, the failure strength is highest at an intermediate length. In this study, the peak failure strength of the fiber-reinforced soil was reached at a fiber length of $12 \mathrm{~mm}$.

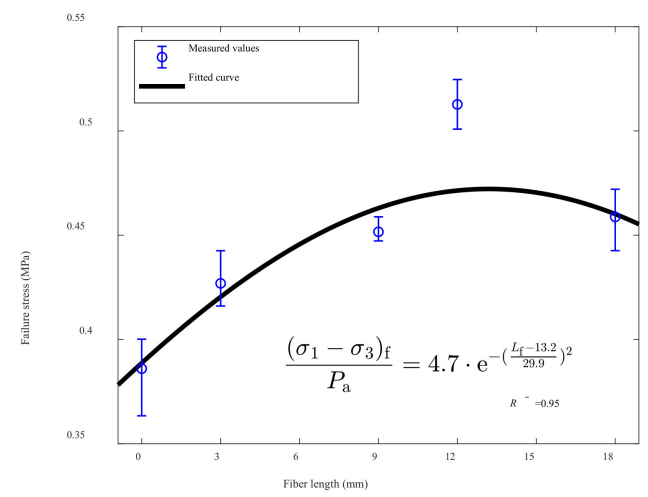

Figure 8. Relationship between the failure stress and fiber length of the fiber-reinforced soil.

(3) Effect of confining pressure

Figure 9 shows the relationship between the failure stress and confining pressure of the studied fiber-reinforced soil. As the confining pressure increased, the failure stress of the fiber-reinforced soils 
showed a linear increasing trend. That is, the greater the confining pressure, the greater the failure strength of the fiber-reinforced soil and the better the reinforcement effect were.

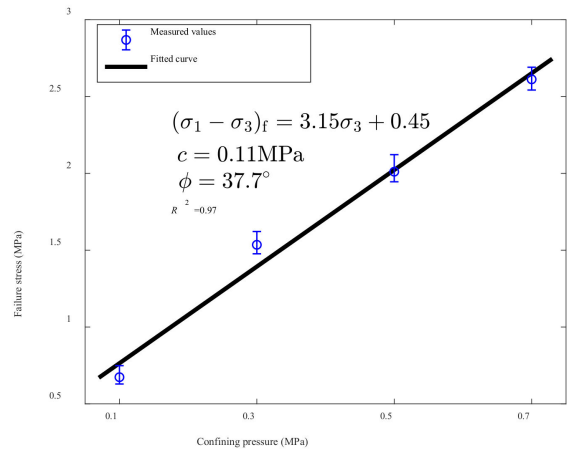

Figure 9. Relationship between the failure stress and confining pressure of the fiber-reinforced soil.

(4) Empirical model for predicting the failure strength of fiber-reinforced soil

Multivariate regression analysis was used to develop an empirical model for predicting the failure strength of fiber-reinforced soil considering three factors:

$$
\frac{\left(\sigma_{1}-\sigma_{3}\right)_{\mathrm{f}}}{P_{\mathrm{a}}}=2.37 \cdot \sin \left(3.48 \beta_{\mathrm{f}}+0.88\right) \cdot \mathrm{e}^{-\left(\frac{\mathrm{L}_{\mathrm{f}}-13.2}{29.9}\right)^{2}} \cdot\left(\frac{\sigma_{3}}{P_{\mathrm{a}}}+1.43\right)
$$

where $\left(\sigma_{1}-\sigma_{3}\right)_{\mathrm{f}}$ is the failure stress of fiber-reinforced soil; $\beta_{\mathrm{f}}$ is fiber content; $L_{\mathrm{f}}$ is fiber length; $\sigma_{3}$ is confining pressure; and $P_{\mathrm{a}}$ is the standard atmospheric pressure of $0.101 \mathrm{MPa}$.

\subsection{Parameter Determination Based on the Duncan-Chang Model}

The stress-strain curves of the fiber-reinforced soil the triaxial tests possessed strain-hardening characteristics, and the relationship of $\left(\sigma_{1}-\sigma_{3}\right)$ with $\varepsilon$ could be fitted by a hyperbolic curve. The stress-strain relationship of the fiber-reinforced soil could be mathematically expressed by the Duncan-Chang model, a nonlinear elastic model [34].

The triaxial test results show that the relationship of $\left(\sigma_{1}-\sigma_{3}\right)$ with $\varepsilon$ in fiber-reinforced soil could be expressed as

$$
\sigma_{1}-\sigma_{3}=\frac{\varepsilon}{a+b \varepsilon}
$$

An approximately linear relationship between $\sigma_{1}-\sigma_{3}$ and $\varepsilon$ can be obtained, as shown in Figure 10:

$$
\frac{\varepsilon}{\sigma_{1}-\sigma_{3}}=a+b \varepsilon
$$

where $\left(\sigma_{1}-\sigma_{3}\right)$ is the stress, $\varepsilon$ is the strain, and $a$ and $b$ are the linear intercept and slope.

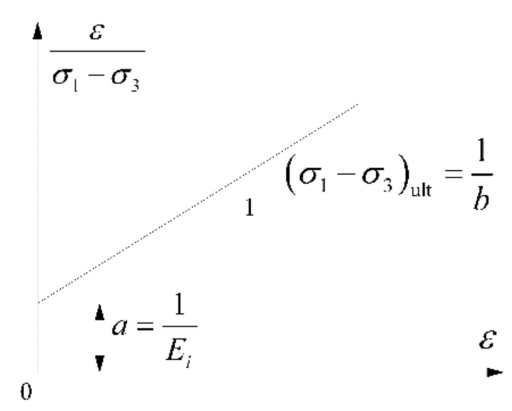

Figure 10. Diagram of the relationship of $\varepsilon /\left(\sigma_{1}-\sigma_{3}\right)$ and $\varepsilon$ 
For triaxial tests, $\mathrm{d} \sigma_{2}=\mathrm{d} \sigma_{3}=0$, and the tangential modulus is

$$
E_{t}=\frac{\mathrm{d}\left(\sigma_{1}-\sigma_{3}\right)}{\mathrm{d} \varepsilon}=\frac{a}{(a+b \varepsilon)^{2}}
$$

At the starting point of the test, $\varepsilon=0, E_{t}=E_{i}$, and the initial tangent modulus $E_{i}$ is

$$
E_{i}=\frac{1}{a}
$$

where $a$ represents the reciprocal of $E_{i}$ during the test.

In Equation (2), if $\varepsilon \rightarrow \infty$, then

$$
\left(\sigma_{1}-\sigma_{3}\right)_{\mathrm{ult}}=\frac{1}{b}
$$

where $b$ represents the reciprocal of the ultimate deviator stress $\left(\sigma_{1}-\sigma_{3}\right)_{\mathrm{ult}}$ corresponding to the asymptote of the hyperbola.

From the triaxial test data, coefficients $a$ and $b$ were found by curve fitting, and then the values of $E_{i}$ and $\left(\sigma_{1}-\sigma_{3}\right)_{\mathrm{ult}}$, the Duncan-Chang model parameters, were determined from Equations (5) and (6) (Table 5).

Table 5. Model parameters of the fiber-reinforced soil.

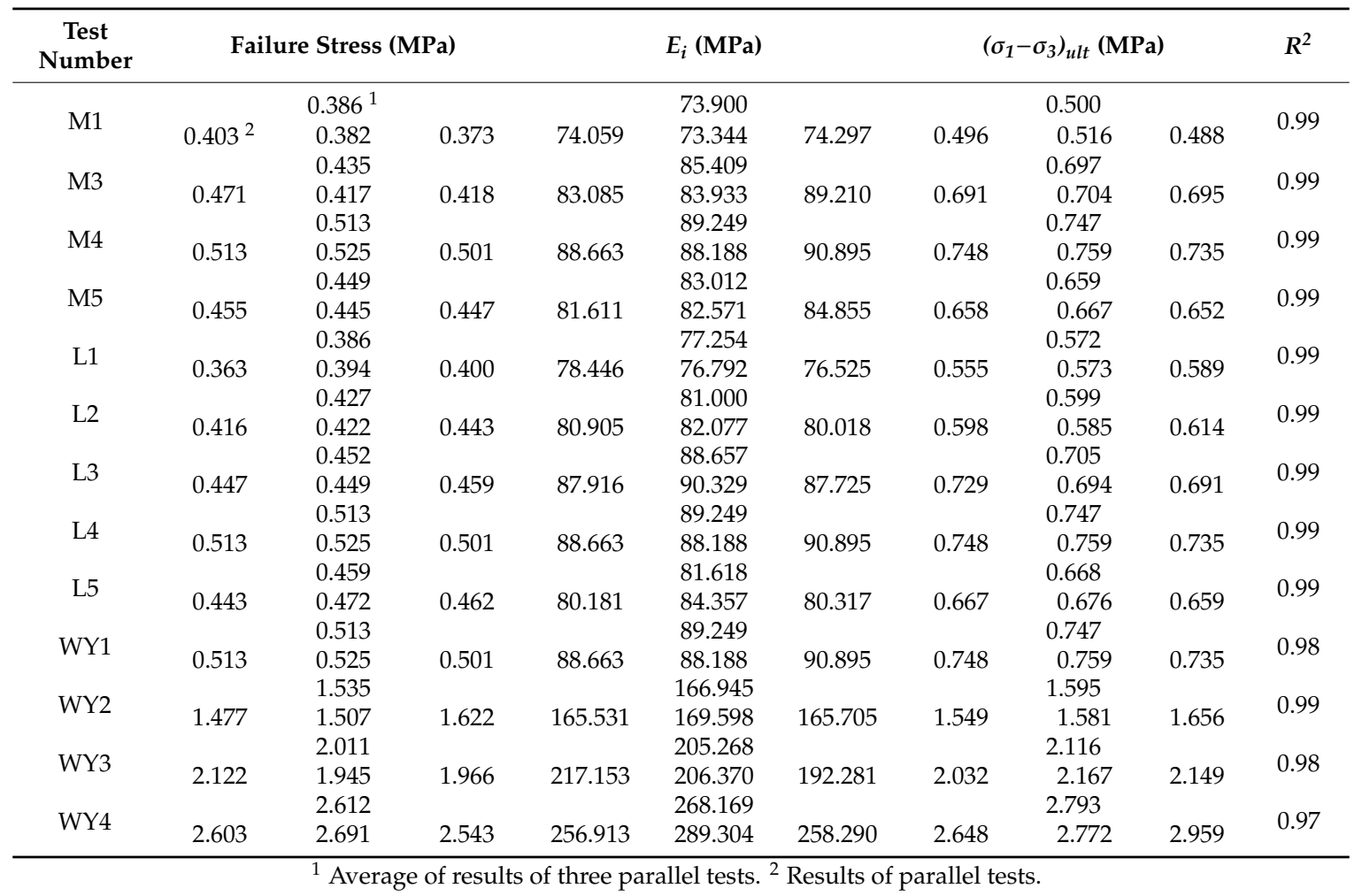

(1) Effect of fiber content

As shown in Figures 11 and 12, with the increase in fiber concentration, the $E_{i}$ and $\left(\sigma_{1}-\sigma_{3}\right)_{\mathrm{ult}}$, the model parameters of the fiber-reinforced soil, first increased then decreased, approximating a sinusoidal trigonometric function, with the peak value near the fiber content of $0.2 \%$. 


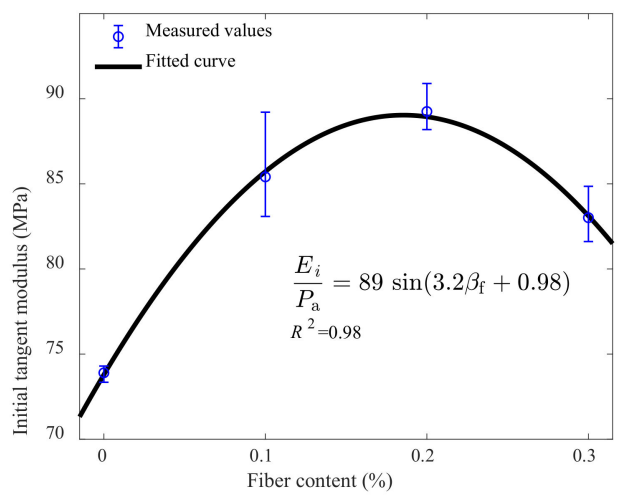

Figure 11. Relationship between $E_{i}$ and the fiber content of the fiber-reinforced soil.

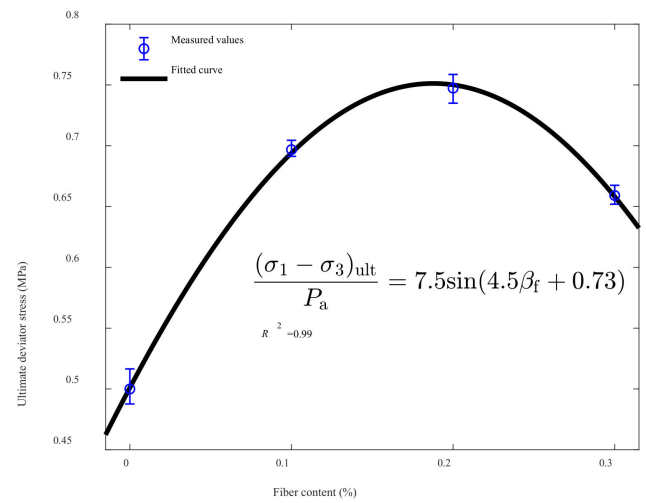

Figure 12. Relationship between $\left(\sigma_{1}-\sigma_{3}\right)$ ult and the fiber content of the fiber-reinforced soil.

Comparing the soil reinforced with the optimal fiber content of $0.2 \%$ to pure fill and fill with a concentration of $0.3 \%$, the $E_{i}$ was $17 \%$ and $8 \%$ higher, and $\left(\sigma_{1}-\sigma_{3}\right)$ ult was $31 \%$ and $13 \%$ higher, respectively, which indicates that fiber concentration has a greater effect on the strength of soil than on its stiffness.

\section{(2) Effect of fiber length}

Figures 13 and 14 show that as the fiber length increased, both $E_{i}$ and $\left(\sigma_{1}-\sigma_{3}\right)_{\text {ult }}$, the fiber-reinforced soil model parameters, first increased and then decreased, approximating a Gaussian function, with a peak value point near the length of $12 \mathrm{~mm}$.

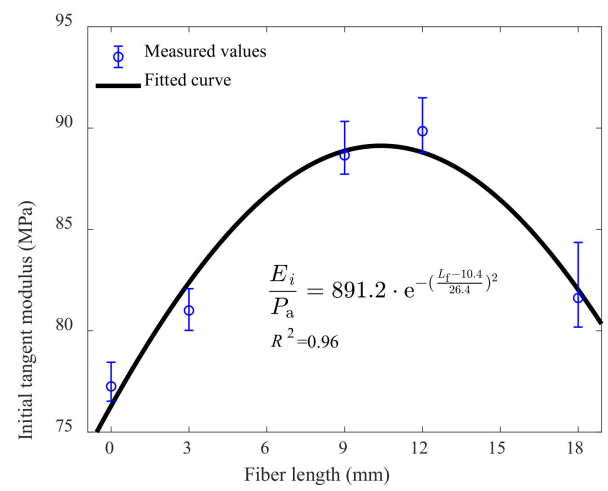

Figure 13. Relationship between $E_{i}$ and the fiber length of the fiber-reinforced soil. 


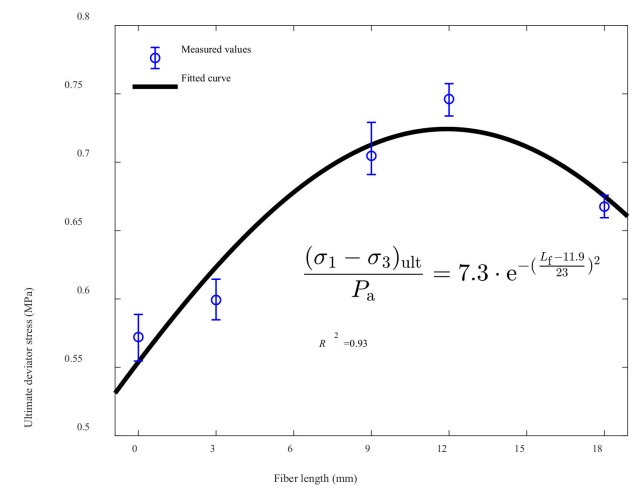

Figure 14. Relationship between $\left(\sigma_{1}-\sigma_{3}\right)_{\mathrm{ult}}$ and the fiber length of the fiber-reinforced soil.

Comparing the soil reinforced with the optimal fiber length of $12 \mathrm{~mm}$ to the pure fill and fill with a fiber length of $18 \mathrm{~mm}$, the $E_{i}$ was $14 \%$ and $7 \%$ higher, and $\left(\sigma_{1}-\sigma_{3}\right)_{\mathrm{ult}}$ was $30 \%$ and $12 \%$ higher, respectively, which indicates that fiber length has a greater effect on the strength of soil than on its stiffness.

\section{(3) Effect of confining pressure}

Figures 15 and 16 show that, as the confining pressure increased, the $E_{i}$ and $\left(\sigma_{1}-\sigma_{3}\right)_{\text {ult }}$, the model parameters of the fiber-reinforced soil, increased, approximating a power function, with power indices of 0.57 and 0.69 , respectively. These findings indicate that confining pressure has a more significant effect on the strength of soil than on its stiffness.

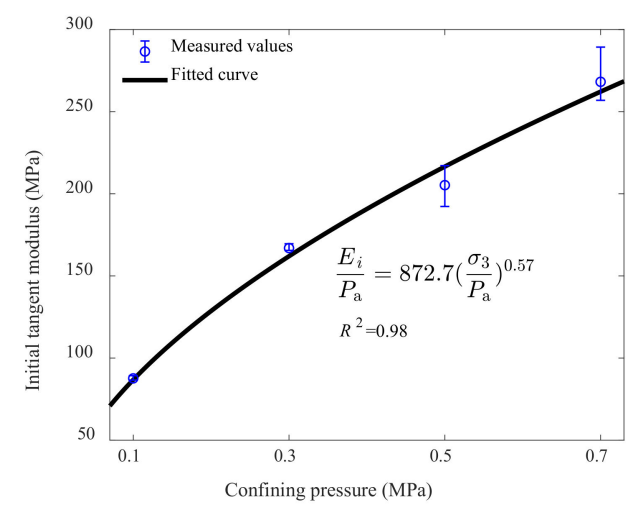

Figure 15. Relationship between $E_{i}$ and the confining pressure of the fiber-reinforced soil.

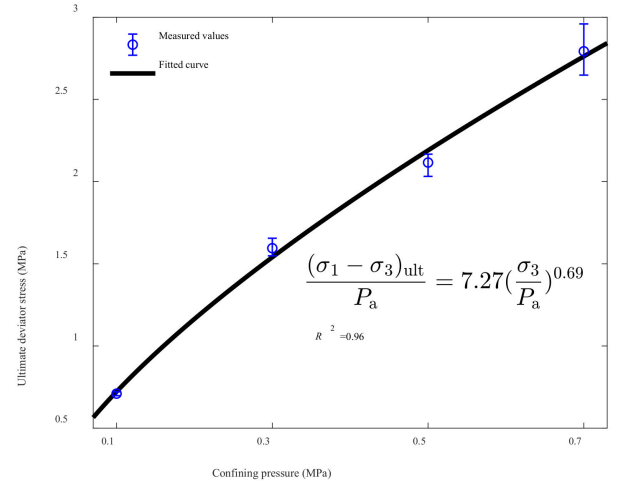

Figure 16. Relationship between $\left(\sigma_{1}-\sigma_{3}\right)$ ult and the confining pressure of the fiber-reinforced soil. 
Considering the effects of fiber content, fiber length, and confining pressure on $E_{i}$ and $\left(\sigma_{1}-\sigma_{3}\right)_{\mathrm{ult}}$, the fiber-reinforced soil model parameters, the predictive models for $E_{i}$ and $\left(\sigma_{1}-\sigma_{3}\right)_{\text {ult }}$ are proposed as follows:

$$
\begin{gathered}
E_{i}=859.64 P_{\mathrm{a}} \cdot \sin \left(3.2 \beta_{f}+0.98\right) \cdot \mathrm{e}^{-\left(\frac{L_{\mathrm{f}}-10.7}{24.3}\right)^{2}} \cdot\left(\frac{\sigma_{3}}{P_{\mathrm{a}}}\right)^{0.57} \\
\left(\sigma_{1}-\sigma_{3}\right)_{\mathrm{ult}}=7.51 P_{\mathrm{a}} \cdot \sin \left(4.5 \beta_{\mathrm{f}}+0.73\right) \cdot \mathrm{e}^{-\left(\frac{L_{\mathrm{f}}-12}{19.5}\right)^{2}} \cdot\left(\frac{\sigma_{3}}{P_{\mathrm{a}}}\right)^{0.69}
\end{gathered}
$$

To verify the accuracy of Equations (7) and (8) for $E_{i}$ and $\left(\sigma_{1}-\sigma_{3}\right)_{\text {ult }}$, we compared the measured values of $E_{i}$ and $\left(\sigma_{1}-\sigma_{3}\right)$ ult with the predicted values (Figures 17 and 18). The values were basically consistent, with correlation coefficients $R^{2}$ over 0.97 . The stress-strain relationship of fiber-reinforced soil can be described by the Duncan-Chang model, and the proposed method for determining $E_{i}$ and $\left(\sigma_{1}-\sigma_{3}\right)_{\text {ult }}$ is feasible. Equations (7) and (8) can accurately predict the parameters of the Duncan-Chang model, and the model can accurately determine the mathematical expressions of the mechanical properties of the fiber-reinforced soils, meaning that these findings can provide a reference for the solution of similar problems.

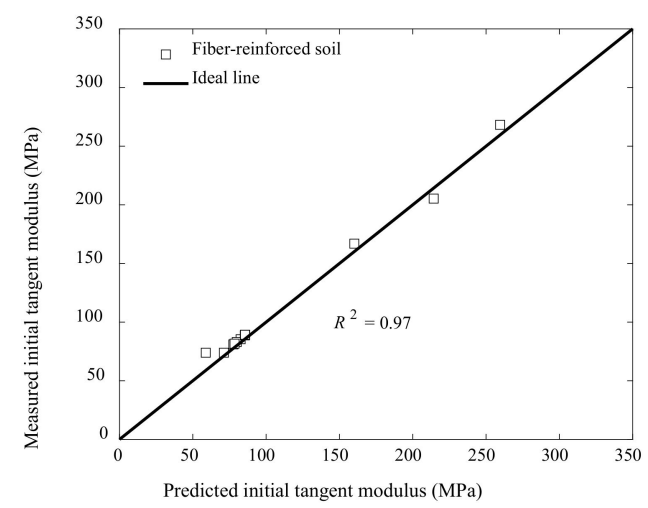

Figure 17. Comparison of the measured and predicted $E_{i}$ of the fiber-reinforced soil.

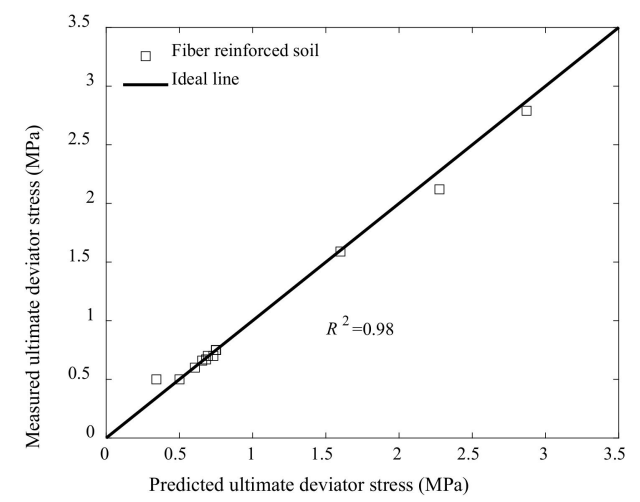

Figure 18. Comparison of the measured and predicted $\left(\sigma_{1}-\sigma_{3}\right)_{\mathrm{ult}}$ of the fiber-reinforced soil.

\section{Conclusions}

This study conducted triaxial compressive tests on Y-shaped fiber-reinforced subgrade fill with different fiber contents, fiber lengths, and confining pressures; and the strength characteristics of the fiber-reinforced soil were analyzed. The following conclusions were drawn:

(1) The strength of the fiber-reinforced soil first increased and then decreased as the fiber content and length increased. The fiber reinforcement effect was the best at a fiber content of $0.2 \%$ and fiber length of $12 \mathrm{~mm}$ in all test conditions. As the confining pressure increased, the strength of the fiber-reinforced soil increased. 
(2) The failure pattern of the fiber-reinforced soil specimens was due to bulging deformation, showing plastic failure characteristics.

(3) Through regression analysis of our test data, an empirical model for predicting the failure strength of fiber-reinforced soil was established. This model considers the fiber content, fiber length, and confining pressure. It can rapidly estimate the failure strength of fiber-reinforced soil and provide a reference for engineering applications.

(4) The stress-strain curve of the fiber-reinforced soil exhibited strain-hardening characteristics and could be fitted by a hyperbolic curve. Thus, the Duncan-Chang model can be used to mathematically describe the stress-strain relationship of the fiber-reinforced soil. A method for calculating $E_{i}$ and $\left(\sigma_{1}-\sigma_{3}\right)$ ult, the Duncan-Change model parameters, was proposed, which provides a reference for the accurate expression of the mechanical properties of heavy-haul railway subgrade.

(5) It is important to note that this work concerned a case study, which is intended to develop a strength empirical model for predicting the strength of the fiber-reinforced fill with a modest number of samples and tests. Accordingly, more tests are necessary to be conducted to further verify the applicability of the proposed models.

Author Contributions: Methodology, investigation, resources, original draft preparation, review and editing, Y.Z.; supervision, X.L. and W.G.; validation, P.L., G.L., and L.W. All authors have read and agreed to the published version of the manuscript.

Funding: This research was funded by the State Key Laboratory of Frozen Soil Engineering, grant number SKLFSE201907, National Key Research and Development Program of China, grant number 2018YFC1505300, National Major Scientific Instruments Development Project of China, grant number, 41627801, National Natural Science Foundation of China, grant number 51678145. The APC was funded by 2018YFC1505300.

Acknowledgments: This work was possible with the equipment support of Northwest Institute of Eco-Environment and Resources. The fibers has been provided by Shanghai Bonin Engineering Fiber Materials Co. LTD, Shanghai, China. The authors are grateful to Pro. Zhang for offering fibers' details.

Conflicts of Interest: The authors declare no conflict of interest.

\section{References}

1. Bao, C.; Ding, J. Researches and applications of fiber reinforced soils. Soil Eng. Found. 2012, 26, 80-83. [CrossRef]

2. Liu, B.; Tang, C.; Li, J.; Wang, D.; Zhu, K.; Tang, W. Advances in engineering properties of fiber reinforced soil. J. Eng. Geol. 2013, 21, 540-547. [CrossRef]

3. Shao, W.; Cetin, B.; Li, Y.; Li, J.; Li, L. Experimental investigation of mechanical properties of sands reinforced with discrete randomly distributed fiber. Geotech. Geol. Eng. 2014, 32, 901-910. [CrossRef]

4. Botero, E.; Ossa, A.; Sherwell, G.; Ovando-Shelley, E. Stress-strain behavior of a silty soil reinforced with polyethylene terephthalate (PET). Geotext. Geomembr. 2015, 43, 363-369. [CrossRef]

5. Muntohar, A.S.; Widianti, A.; Hartono, E.; Diana, W. Engineering properties of silty soil stabilized with lime and rice husk ash and reinforced with waste plastic fiber. J. Mater. Civ. Eng. 2013, 25, 1260-1270. [CrossRef]

6. Machado, S.L.; Vilar, O.M.; Carvalho, M.F. Constitutive model for long term municipal solid waste mechanical behavior. Comput. Geotech. 2008, 35, 775-790. [CrossRef]

7. Kutara, K.; Miki, H.; Horiya, S.; Ishizaki, H.; Fujiki, H. Mechanical behavior of reinforced soil by continuous threads. Proc. Geotext. Symp. 1988, 3, 27-33. [CrossRef]

8. You, B.; Xu, H.; Dong, J. Triaxial Tests of Expansive soil reinforced with basalt fiber. J. Disaster Prev. Mitig. Eng. 2015, 35, 503-507+514. [CrossRef]

9. Gao, L.; Hu, G.; Xu, Y.; Hu, Y.; Gong, Y. Triaxial tests clay reinforced by basalt fiber. Chin. J. Geotech. Eng. 2017, 39, 198-203. [CrossRef] 
10. Liu, F.; Sun, H.; Ge, X. Glass Fiber-reinforced sand studied by triaxial experiments. J. Shanghai Jiaotong Univ. 2011, 45, 762-766+771. [CrossRef]

11. Mirzababaei, M.; Miraftab, M.; Mohamed, M.; McMahon, P. Unconfined compression strength of reinforced clays with carpet waste fibers. J. Geotech. Geoenviron. Eng. 2013, 139, 483-493. [CrossRef]

12. Akbulut, S.; Arasan, S.; Kalkan, E. Modification of Clayey Soils using scrap tire rubber and synthetic fibers. Appl. Clay Sci. 2007, 38, 23-32. [CrossRef]

13. Consoli, N.C.; Casagrande, M.D.T.; Coop, M.R. Performance of a fibre-reinforced sand at large shear strains. Géotechnique 2007, 57, 751-756. [CrossRef]

14. Cristelo, N.; Cunha, V.M.C.F.; Dias, M.; Gomes, A.T.; Miranda, T.; Araújo, N. Influence of discrete fibre reinforcement on the uniaxial compression response and seismic wave velocity of a cement-stabilised sandy-clay. Geotext. Geomembr. 2015, 43, 1-13. [CrossRef]

15. Plé, O.; Lê, T.N.H. Effect of polypropylene fiber-reinforcement on the mechanical behavior of silty clay. Geotext. Geomembr. 2012, 32, 111-116. [CrossRef]

16. Michalowski, R.L.; Zhao, A. Failure of Fiber-Reinforced Granular Soils. J. Geotech. Eng. 1996, 122, $226-234$. [CrossRef]

17. Wood, D.M.; Russell, A.R.; Ibraim, E.; Diambra, A. Determination of fibre orientation distribution in reinforced sand. Géotechnique 2007, 57, 623-628. [CrossRef]

18. Ibraim, E.; Fourmont, S. Behaviour of sand reinforced with fibres. In Soil Stress-Strain Behaviour: Measurement, Modelling and Analysis. A Collection of Papers of the Geotechnical Symposium, Rome, Italy, 16-17 March 2006; Springer: Amsterdam, The Netherlands, 2006.

19. Ibraim, E.; Diambra, A.; Russell, A.R.; Wood, D.M. Assessment of laboratory sample preparation for fibre reinforced sands. Geotext. Geomembr. 2012, 34, 69. [CrossRef]

20. Diambra, A.; Ibraim, E.; Wood, D.M.; Russell, A.R. Fibre reinforced sands: Experiments and modelling. Geotext. Geomembr. 2010, 28, 238-250. [CrossRef]

21. Ang, E.C.; Erik Loehr, J. Specimen Size Effects for Fiber-Reinforced Silty Clay in Unconfined Compression. Geotech. Test. J. 2003, 26, 191-200. [CrossRef]

22. Wang, D.; Tang, C.; Li, J.; Liu, B.; Tang, W.; Zhu, K. Shear strength characteristics of fiber-reinforced unsaturated cohesive soils. Chin. J. Geotech. Eng. 2013, 35, 1933-1940.

23. Kumar, A.; Walia, B.S.; Bajaj, A. Influence of fly ash, lime, and polyester fibers on compaction and strength properties of expansive soil. J. Mater. Civ. Eng. 2007, 19, 242-248. [CrossRef]

24. Welker, A.L.; Josten, N. Interface Friction of a Geomembrane with a Fiber Reinforced Soil. In Proceedings of the Slopes and Retaining Structures under Seismic and Static Conditions, Austin, TX, USA, 24-26 January 2005; American Society of Civil Engineers: Austin, TX, USA, 2005; pp. 1-8.

25. Prabakar, J.; Sridhar, R.S. Effect of random inclusion of sisal fibre on strength behaviour of soil. Constr. Build. Mater. 2002, 16, 123-131. [CrossRef]

26. Cai, Y.; Shi, B.; Gao, W.; Chen, F.; Tang, C. Experimental study on engineering properties of fibre-lime treated soils. Chin. J. Geotech. Eng. 2006, 28, 1283-1287. [CrossRef]

27. Wu, J.; Zhang, X. Study on strength of polypropylene fiber reinforced expansive soil. Soil Eng. Found. 2010, 24, 71-73+76. [CrossRef]

28. Wang, P.; Tang, C.; Sun, K.; Chen, Z.; Xu, S.; Shi, B. Experimental investigation on consolidation properties of fiber reinforced municipal sludge. J. Eng. Geol. 2015, 23, 687-694. [CrossRef]

29. Zhao, N.; Jing, L. Experimental study on strength properties of texsol. J. Chongqing Univ. Technol. (Nat. Sci.) 2010, 24, 47-51+68. [CrossRef]

30. Kumar, A.; Walia, B.S.; Mohan, J. Compressive strength of fiber reinforced highly compressible clay. Constr. Build. Mater. 2006, 20, 1063-1068. [CrossRef]

31. Tang, C.; Gu, K. Strength behaviour of polypropylene fiber reinforced cement stabilized soft soil. Chin. Civ. Eng. J. 2011, 44, 5-8. [CrossRef]

32. Sobhan, K.; Mashnad, M. Mechanical stabilization of cemented soil-fly ash mixtures with recycled plastic strips. J. Environ. Eng. 2003, 129, 943-947. [CrossRef] 
33. Tang, C.S.; Shi, B.; Zhao, L.Z. Interfacial shear strength of fiber reinforced soil. Geotext. Geomembr. 2010, 28, 54-62. [CrossRef]

34. Li, G. Advanced Soil Mechanics, 2nd ed.; Tsinghua University Press: Beijing, China, 2004; pp. 50-56.

Publisher's Note: MDPI stays neutral with regard to jurisdictional claims in published maps and institutional affiliations.

(C) 2020 by the authors. Licensee MDPI, Basel, Switzerland. This article is an open access article distributed under the terms and conditions of the Creative Commons Attribution (CC BY) license (http://creativecommons.org/licenses/by/4.0/). 